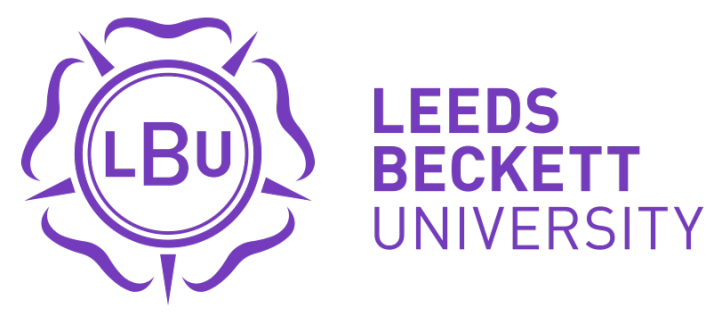

Citation:

Curran, K and Drust, B and Richardson, D (2014) 'I just want to watch the match': a practitioner's reflective account of men's health themed match day events at an English Premier League football club. Soccer and Society, 15 (6). 919 - 933. ISSN 1466-0970 DOI: https://doi.org/10.1080/14660970.2014.920626

Link to Leeds Beckett Repository record:

https://eprints.leedsbeckett.ac.uk/id/eprint/2003/

Document Version:

Article (Updated Version)

The aim of the Leeds Beckett Repository is to provide open access to our research, as required by funder policies and permitted by publishers and copyright law.

The Leeds Beckett repository holds a wide range of publications, each of which has been checked for copyright and the relevant embargo period has been applied by the Research Services team.

We operate on a standard take-down policy. If you are the author or publisher of an output and you would like it removed from the repository, please contact us and we will investigate on a case-by-case basis.

Each thesis in the repository has been cleared where necessary by the author for third party copyright. If you would like a thesis to be removed from the repository or believe there is an issue with copyright, please contact us on openaccess@leedsbeckett.ac.uk and we will investigate on a case-by-case basis. 
"I just want to watch the match" A practitioner's reflective account of men's health themed match day events at an English Premier League Football Club.

${ }^{1}$ Kathryn Curran, ${ }^{2}$ Barry Drust and ${ }^{2}$ Dave Richardson

${ }^{1}$ Academic Group of Engineering, Sports and Sciences, University of Bolton, Bolton, United Kingdom.

${ }^{2}$ Research Institute of Sport and Exercise Sciences, Liverpool John Moores University, Liverpool, United Kingdom

Corresponding Author Information:

Dr Kathryn Curran

University of Bolton

Deane Road

Bolton

BL3 5AB

Tel: 01204903117

E-mail: $\underline{\text { K.Curran@ @olton.ac.uk }}$ 


\title{
"I just want to watch the match" A practitioner's reflective account of men's health themed match day events at an English Premier League Football Club.
}

\begin{abstract}
This study reflects on the effectiveness and delivery of a series of health themed match day events at an English Premier League Football Club which aimed to create awareness and motivate men to adopt recommended health behaviours. A range of marketing techniques and activities were adopted within a targeted space and time to increase men's exposure to health information. The first author adopted a practitionercum-researcher role and was immersed in the planning and delivery of the events utilising the principles of ethnography. Data was predominately collated through observations and personal reflections logged via autobiographical field notes. Data was analysed through abductive reasoning. In general, men were reluctant to engage in health related behaviours on match days. However, subtle, non-invasive approaches were deemed successful. Positive outcomes and case studies from the latter techniques are presented and suggestions for effective strategies that will better engage men in health information and behaviours are made.
\end{abstract}

Key words: Premier League, English Football, Football in the Community, Men, Health. 


\section{Introduction}

In the UK, there is a particular concern regarding the physical activity and health behaviours of men. National statistics indicate that the health of men in the UK is poor. A recent and comprehensive report by White et al. ${ }^{1}$ entitled The State of Men 's Health in Europe highlighted that more than 100,000 men in the UK die prematurely (i.e., under the age of 75 years) each year and many of these deaths are a result of noncommunicable lifestyle diseases such as fat related cancers, diabetes and cardiovascular disease. Compared to women, men in the UK have a lower life expectancy (i.e., 77.4 years for men compared to 81.6 years for women), are three times more likely to become dependent on alcohol, more likely to commit suicide and twice as likely to die from a circulatory disease. ${ }^{2}$ Furthermore, $65 \%$ of men in the UK are currently classified as overweight or obese $(\mathrm{BMI}<25)$ and only $39 \%$ of the male population are currently meeting the Chief Medical Officers (CMO) recommendations for physical activity. ${ }^{3}$

The poor state of men's health in the UK is further exacerbated by the apparent reluctance of men to frequently engage with traditional community health services. Although evidence suggests that men are no less likely than women to consult their GP (General Practitioner) at a given level of severity for a given condition type, ${ }^{4}$ White et al. $^{5}$ reported that men are less likely than women to access health services frequently. There is a large body of empirical research to support the concept that men are reluctant to seek preventative help from health professionals. ${ }^{6}$ The reasons cited for this poor level of engagement include the limited opening hours of health services, excessive delays for appointments and/or a lack of vocabulary required to discuss sensitive issues. ${ }^{7}$ Social constructions of masculinity have also been implicated as 
explanations for men's poor uptake of health services. The writings of Harrison, ${ }^{8}$ Courtney, ${ }^{9}$ Robertson ${ }^{10}$ and Gough and Robertson ${ }^{11}$ for example, highlight the negative impact that masculinity and male role socialisation can have on influencing men's health behaviours and thus, men's health status. For example, Gough ${ }^{12}$ reported that concealing vulnerability is often associated with male role socialisation with men not wishing to appear weak by seeking help and engaging with health services. Furthermore, Gough ${ }^{13}$ identified that traditional health care and health advice is typically dominated by women friendly practices and therefore men can be regarded, and often regard themselves, as intruders in a female land.

As men's uptake of traditional health services has been highlighted as an area of concern, it has been argued that health services need to reach out to men using alternative health intervention techniques. ${ }^{14}$ White and Witty ${ }^{15}$ proposed that the setting in which 'male targeted' interventions are delivered is an important factor in engaging men with health. The UK Government's White Paper Healthy People, Healthy Lives,${ }^{16}$ identified the community as an appropriate setting to engage men in positive health behaviours. Wilkins and Baker ${ }^{17}$ suggested that the most appropriate community settings to deliver health messages are in places that men already go and where they are more likely to feel comfortable. Examples of such places include community groups or forums and groups associated with sport, sports events and/or sports stadia.

Targeting men's health during their leisure time has been successfully achieved through associations with professional sports teams. ${ }^{18}$ The Tackling Men's Health intervention ${ }^{19}$ is a recent example of a health promoting intervention targeting men 
with health improvement schemes at large UK sports stadia. The intervention targeted men attending popular rugby league matches, with the aim of promoting men's engagement with community health services and thus, promoting improved health and wellbeing. The intervention achieved strong rates of engagement with the target group and received positive feedback from attendees of the stadium.

More recently, the Premier League Health programme funded by the UK Football Pools (2009-2012) targeted male football supporters (and other men who lived in the local community). This programme was delivered by 16 English Premier League Football Clubs through their Football in the Community schemes (FitC). The Premier League Health programme used the unique opportunity that football offers to reach some of the most marginalised individuals in the community. ${ }^{20}$ Premier League Health aimed to raise men's awareness, and subsequently engage men, in health related behaviours at their respective football clubs both on match days and non-match days (i.e., through organised physical activity sessions, access to health services). Awareness and engagement in health behaviours was achieved through a variety of approaches with engagement tools being primarily based on the assumption that men will respond to health messages offered in places that they feel comfortable. ${ }^{21}$

It can be argued that the findings of the Tackling Men's Health intervention and the Premier League Health programme demonstrate that men are willing to engage in health behaviours if the services provided are sensitive to their needs and masculine identities. Whilst this evidence is useful for building an evidence-base in, and advancing, men's health initiatives, academics have argued that more needs to be done. White and Witty ${ }^{22}$ argued that there is a need to further examine the effectiveness 
of such programmes in order to better understand how we can engage men in health information and behaviours. Furthermore, it has been suggested that men will only achieve the highest level of wellbeing when health promotion programmes are built on an understanding of the social factors underpinning men's health related decision making practices. ${ }^{23}$ It would appear necessary therefore, to undertake further evaluation of what aspects of a community health promotion activity work for men and why, and conversely identify activities that do not work and why. It has been argued that generating evidence from local practice will provide valuable insights into overall best practice which can therefore translate into grassroots health promotion programmes for men. ${ }^{24}$ Carmichael and Miller ${ }^{25}$ suggested that novel methodologies (i.e., those that allow for plunging into the culture and environment of research setting) such as practitioner-researcher approaches, allow for truthful and powerful evidence to be generated.

With these thoughts in mind, this paper focuses on the accounts and personal reflections of the first author (practitioner-cum-researcher) during the development and delivery of a series of community based health themed match day events through Everton Football Club's Premier League Health programme. Each match day event aimed to engage men in health related information and behaviours in a community setting, during their leisure time. The study examines the effectiveness of, and barriers to, promoting and engaging male football fans in positive health related behaviours and messages at an English Premier League football stadium (i.e., a community setting) on match days. Moreover, this study aims to provide valuable insights into the best ways to communicate health messages to men and offer suggestions for effective 
strategies that will better engage men in health information and behaviours in a community setting.

\section{Profiling the Researcher}

At this point it appears relevant to identity to the reader that throughout the duration of this research, the first author was employed as a full time member of staff by Liverpool John Moores University, School of Sport and Exercise Sciences (LJMU SPS) but was based within the grounds of Goodison Park, home of Everton Football Club. It was here that the author worked full-time with/for Everton in the Community (Everton Football Club's Football in the Community scheme) co-ordinating their Premier League Health project and conducting immersed practitioner research. The author's role as a practitioner-researcher involved the day-to-day management and continuous development of the Premier League Health programme. Furthermore, this role encouraged the author to examine the current men's health and Football in the Community based literature and design and conduct appropriate research to address the gaps in knowledge.

It is anticipated that by setting the scene and clarifying the author's position at this point, the reader can travel through this paper with the knowledge of the author's set up and operational role during this research.

\section{Methods}

During this study, six health promoting match day events were organised by the author over a period of eight months. The match day events took place both in and around Everton Football Club (an English Premier League football club) as part of Everton in 
the Community's Premier League Health programme. The match day events all aimed to create awareness of a particular health theme and motivate men to consider adopting and/or engaging in recommended health behaviours. Health themes were dictated by the programme funding body and included physical activity, cancer, sexual health, mental health, alcohol awareness and smoking cessation. Where possible, match day health themes were chosen to align with regional and national health awareness days, for example, national alcohol awareness week, national no smoking day and World cancer day. During each event, project staff worked alongside community health service providers and key organisations working in relevant fields in order to promote appropriate local health services.

In order to increase the awareness of a particular health message, a range of marketing techniques were adopted within a targeted space and time. According to Walsh et al. ${ }^{26}$ marketing has been advocated as a powerful tool for segmenting, profiling, and targeting specific populations in public health messages. Information on the health themed match day event were uploaded onto the official football club website, independent fan websites and a variety of social networking websites, approximately one week prior to the event. Simultaneously, an e-mail was distributed to season ticket holders and a targeted press release was produced for the local media by the football club communications department. It was envisaged that by increasing the awareness of the event and the aligned health message, that acceptance and engagement in health behaviours and messages on the match day would be amplified.

On the day of each of the match day events, dissemination of the health messages occurred both in and around the stadium through a range of promotional materials 
such as the distribution of leaflets and health themed car air fresheners, a series of health themed awareness bathroom stickers installed into the male toilets throughout the stadium and a page of health literature was contained in the official match day programme. Additionally, specific health information were transmitted pre, post and during the match day in a series of multifaceted multimedia outputs including Bluetooth messages to mobile phones, large visual screen images and verbal health information relayed by the announcer both pre match and during the half time interval. Such techniques were based on the premise that men will engage in health behaviours in places that they already go and feel comfortable. ${ }^{27}$ As a direct result of the marketing and promotion of the event, and the gender sensitive approach adopted, it was expected that men would wish to engage with health information on match days. In anticipation of the demand for health services, health experts from relevant national and local organisations were available on the day for male fans to engage with. These health partners were based at a health station inside the grounds of the stadium at each match day event.

\section{Research Design}

In order to become immersed in the culture and environment of research setting and to allow for truthful and powerful evidence to be generated, ${ }^{28}$ the author adopted a practitioner-cum-researcher role throughout the study. ${ }^{29}$ The author was responsible for the planning and delivery of all health themed match day events and for the collection of data. Carmichael and Miller ${ }^{30}$ suggested that the use of practitionerresearchers is an appropriate and powerful method of plunging deep into the culture and environment of the research setting in ways that would be very difficult to achieve otherwise. 
Prior to data collection ethical consent was sought and granted by Liverpool John Moores University ethics board. Furthermore, written consent was gained from Everton Football Club that permitted the use of the club name in all related dissemination and publication of the work. Furthermore, any publication of such material resulting from the work was subject to final 'proof' approval from an appropriate representative of the football club. During each match day event the author adopted principles of ethnography and observational research. ${ }^{31}$ Specifically, data was collected through observations and reflections logged via autobiographical field notes. ${ }^{32}$ Typically, field notes were made in the first authors' office after the events of the day had ceased. These initial field notes were then used to form the framework of further reflective accounts. ${ }^{33}$ Data was also collected via e-mails received from match day attendees and health service staff. This relaxed and informal reflective methodology allowed for sense making and encouraged the practitioner to learn from the knowledge gained in action. In essence, the researcher was able to comprehend a greater understanding of the situation, and place specific encounters and events into fuller and more meaningful contexts that were useful for explaining human behaviour. $^{34}$

In this study, knowledge was predominately gained from the first hand experiences of the first author within a community setting. The author learnt from and reflected upon these experiences through the construction of autobiographical field notes using principles of autoethnography. ${ }^{35}$ In line with a constructivist approach, ${ }^{36} \mathrm{I}$ (the first author) endeavour to show you (the reader) what I know, what I saw and how I saw it. $^{37}$ 


\section{Data Analysis and Representation}

The author engaged in a period of close reading in order to become immersed in the data. ${ }^{38}$ At this stage initial ideas and thoughts were recorded. Following this, principles of content analysis were adopted by the researcher in order to identify and categorise themes arising from the data. ${ }^{39}$ Data was analysed through abductive reasoning. ${ }^{40}$ Deductive analysis (based on presented evidence) followed by inductive analysis ensured that relevant theoretical and contextual themes and categories emerged from the data. The data and themes were then presented by the author to the co-authors by means of co-operative triangulation. ${ }^{41}$ The co-authors critically questioned the analysis and cross-examined the data and themes. This process allowed for alternative interpretations of the data to be offered and for a consensus to be reached. The author and co-authors discussed the data and emergent themes until an acceptable consensus had been reached. This process allowed the first author to refine the specifics of each theme and generate clear definitions and names for each theme.

Data is represented through a series of themed narrative accounts in order to capture 'moments' from applied observations and reflections to give the reader a greater understanding of the lived experiences of the author. The first author's field note extracts and personal reflections are presented as italics within the text. Furthermore, the voice of the football fan and health practitioner (captured via e-mails received from match day attendees and health service staff) are also utilised in this study to illustrate the personal experiences of others. This data is represented through verbatim citations and identified as single spaced lines and a smaller font (i.e., font 10) within the text. Pseudonyms are used throughout the results section. Finally, a number of images are 
presented in order to help bring-to-life aspects of the data and supplement the text. The following results and discussion sections outline what the authors perceive to be the relevant issues emerging from the expansive data collected.

\section{Results}

\section{Avoidance and lack of engagement with health service staff}

In contrast to existing research ${ }^{42}$ only a small number of men engaged with health services at the stadium on match days. In order to increase men's awareness of, and engagement in, health messages, a range of services were deliberately placed in areas where men frequently attend and feel comfortable (i.e., an English Premier League football match). However, whilst, information on the health themed match day event was advertised through a range of different mediums in the lead up to the event, it appeared that this had little or no effect on the 'engagement behaviour' of the male football supporters. To put this into context, approximately 32,000 male fans attended each football match, therefore, a total of roughly 192,000 male bodies were present over the six health themed match day events. Whilst this figure includes the possible repeat attendances of the 26,048 male season ticket holders it is still a vast number of men that were potentially exposed to the match day health themes. However, the health experts present on each of the match days only engaged with a total of 14 men.

The following reflection captures the frustrations of the author in relation to the male football fans lack of engagement with health service staff and their lack of interest in the health stations: 
Practitioner Reflection 16/02/2010, 14:05:

The health stations at the match day events just don't seem to be working. It seemed like such a good idea; men aren't going out of their way to access health services so we'll put health experts in a place where they are already going! Thousands of men are passing by our health stations in the hours leading up to kick off and it's [the health station] right there under their noses and yet they just don't want to know. When I watch them [the male football fans], they mostly seem to be in a rush. It's like they know where they are heading to and they don't want anything, or anyone, to interrupt them. It was the same a couple of hours before the match kicked off, when it's less busy and more chilled out. But they (the men we are trying to engage with) would rather go and watch the players park their cars than stop and talk to us about their health. It's hard to put into words just how frustrated and disappointed I am with this outcome. It took a lot of hard work to get these health stations accepted by the Club and I think I've even put a strain on some professional relationships whilst arguing the case for them.

Figure 1. (below) epitomises the men's behaviour on a typical match day. Specifically, the scene captures the first author's frustrations (highlighted in the reflection above) as we see hoards of men preferring to loiter around the area where the first team players park their cars rather than stop and talk to health professionals about their health in the hours leading up to kick-off.

INSERT FIGURE 1 
The dissemination of health messages through the distribution of leaflets also had little impact on the men's engagement with health messages and health services. Leaflets were generally disregarded and when approached, many men verbalised such comments as, "Not now love/girl" and "No thanks, I just want to watch the match."

\section{Branded freebies and subliminal messages; a step in the right direction}

Football club branded health themed car air fresheners, however, had a greater acceptance than health themed leaflets and information stations and appeared to be a step in the right direction for engaging men in health messages at an English Premier League football club on match days. Car air fresheners were designed in the profile of a football shirt, printed in the corresponding colour of the home team and displayed printed signs and symptoms of bowel cancer (see figure 2. below). Over 5,000 air fresheners were distributed to male fans during one match day event in various locations in and around the stadium grounds, with men appearing content to receive them.

\section{INSERT FIGURE 2}

The thoughts of the author following the cancer awareness match day event are captured in the following reflection:

Practitioner Reflection 05/12/2009, 16:30:

Today was interesting! A couple of weeks ago we handed out health information leaflets and not many men took them. Those that did take a leaflet tended to stuff them in their pockets very quickly or threw them on the floor. Today we handed out health 
information again, but this time it was printed on car air fresheners. I was amazed by the difference in response! Not only did everyone want one, but men even came up asking if they could have another couple for their mates. I know it's not because of the health messages that people want them, but that doesn't matter, as soon as they are dangling in front of them in the car, they won't be able to escape the health messages printed on them. It's only one small step for health promotion but perhaps one giant leap for health promotion with men?

This finding highlights the power of the football club brand ${ }^{43}$ and suggests that health practitioners are able to disseminate health information material to men on match days. However, in order to create interest and acceptance the health messages/material need to be in a form that is tangible, it must be complimentary and it is advisable that it reflects the brand of the football club (i.e., colours and logo) without infringing upon it. It is also important that the health messages do not drown the merchandise. Instead, subtle subliminal messages seemed more appropriate for these products so that they are still deemed masculine and therefore appealing to our target audience.

\section{Engagement 'inside' the stadium}

Specific health information transmitted both pre match and during the half time interval via a series of multifaceted multimedia outputs (including bluetooth messages to mobile phones, large visual screen images, verbal health information relayed by the stadium announcer and health literature in the official match day programme) were generally considered welcome by the target population in comparison to invasive engagement approaches (i.e., stopping men to talk and handing them health information leaflets). These methods of engagement also appeared not to impose on, 
nor contaminate, the men's match day experience. Furthermore, these methods of engagement occurred within the confines of the football stadium. It could be argued that, when the men were inside the stadium, they became a more captive audience. Once inside, the stadium the men appeared more settled and were (generally) more likely to connect with health information than when they were outside the stadium (i.e., get me now I'm in). Typically, the experience outside of the stadium before the match involved the intricate navigation through large crowds in order to get inside the ground, get to your seat and get settled before kick-off. It appears that such a hectic environment is not conducive to the promotion and/or receipt of health related information.

Another example of the non-invasive and more subliminal approach to engaging the men inside the ground was the use of the cancer awareness vinyl bathroom stickers (see figure 3). These health awareness raising stickers were provided by the local cancer network service (stickers were produced for a larger social marketing campaign) and were installed into the male toilets throughout the stadium by the first author prior to a cancer awareness health themed match day event. The stickers aimed to raise awareness of the signs and symptoms of prostate and bowel cancer in an informal male dominated setting.

\section{INSERT FIGURE 3}

In the subsequent months, the first author received the following feedback via e-mail.

E-mail received 01/02/2010, 09:17: 
"Dear Kathryn, After going to the bathroom in the Park End of the Goodison Stadium my awareness was raised by the large sticker in relation to prostate and bowel cancer. I already had a slight problem with my prostate, but after reading the symptoms in relation to the bowel problems, I realised that I had some of the symptoms. I have since been to the doctors, had a CAT scan, been diagnosed with bowel cancer and had an operation to remove the problem. I feel that most males of my age and generation are not aware of the risks in relation to both bowel and prostrate problems and, like myself, would probably not go to seek advice from there General Practitioner, I feel that the Premier League Health bathroom sticker campaign alerts people and makes them far more aware of the potential risks to them."

Peter, Male, 51, Liverpool.

The following reflection captures the thoughts and feelings of the author upon receiving this information;

Practitioner Reflection 25/01/2010, 10.00:

This week I received an e-mail from a man who had realised that he had significant cancer symptoms after reading one of our cancer awareness bathroom stickers. I was quite emotional after receiving this information. The day I put the stickers up in the male toilets throughout the stadium, was a freezing cold December day and nobody wanted to help me with it (I don't blame them!). I was freezing cold, my fingers were red raw, the toilets were pretty unpleasant and I felt really lonely. I have always recalled this day as one of the only days that I haven't enjoyed since starting this project. Yet now I know that my actions on this day may have contributed to saving this man's life. This just shows that we can make a difference and men are actually taking notice of some of the things we have been doing. I have a very different feeling about that cold lonely day in December now.

This data reinforces the concept that health promotion within an English Premier League Football Club is possible and that it can be both efficient and effective if the correct methods are adopted for capturing the attention of your target audience. 


\section{A take-home message}

Following each match day awareness event, an e-mail was sent by the first author to health service staff that had been involved in the match day event. The purpose of the e-mail was to determine the usefulness and impact of the event to their organisation. An unanticipated finding emerged that the majority of organisations reported significantly higher traffic on their website and/or phone line in the one to two weeks following the match day event. The following e-mail extract is an example of this finding:

E-mail received 20/02/2010, 13:45:

"Hi Kathryn, We had a great time on Wednesday, especially as the Blues won too!!! The following day we received 16 requests for postal chlamydia kits via our website or text system which is a significant increase on the average daily number of testing requests. If anyone else mentions that they heard about us via the match day awareness event we will be sure to let you know. Regards, Rachel."

As the organisation's website and phone number were predominantly advertised through a series of branded multifaceted multimedia outputs, this finding again supports the concept that non-invasive health promotion messages that are branded with the football club logo were better received, and thus, more successful. This finding also supports the theory that men live in the $n o w^{44}$ and so when we market health information to men we should take into account that men will typically concentrate on what is currently happening (in this regard, a football match) and are more likely to take on board information targeted at them in their down-time. Therefore a 'take home' health message is likely to be more successful than a message men must attend to whilst other stimuli are taking place.

\section{Discussion}


In 2009, White and Witty ${ }^{45}$ asserted that more evidence of the impact of sport and sports stadia on men's health engagement was needed. This study aimed to contribute to this call for research by understanding the effectiveness of, and barriers associated with, promoting, and engaging male football fans in, health related behaviours and messages at an English Premier League football stadium on match days.

Through the use of reflective methodologies, this study has provided contextual reallife information which offers valuable insights into men's engagement with health messages and behaviours on a match day at an English Premier League football club. The findings also formulate a number of important messages and future directions for men's health practitioners/researchers to take into consideration.

White and Witty ${ }^{46}$ and Robertson et al. ${ }^{47}$ proposed that the setting where male targeted interventions are delivered is an important factor in men's engagement with health services. Moreover, Wilkins and Baker ${ }^{48}$ suggested that men will respond to health messages offered in places that they already go and feel comfortable such as sports stadia. This finding was supported by the Tackling Men's Health intervention which concluded that the delivery of a men's health intervention at large UK Rugby stadia was feasible and achieved good levels of engagement. In contrast, the Premier League Health health themed match day awareness events at this large UK football club did not appear to achieve such levels of engagement with men in and around the stadium. It would appear that whilst there is an appeal to use sport, and sports stadia in particular, for engaging men in health messages, one size may not fit all. Specifically, we cannot assume that male supporters will absorb health messages in and around all sport stadia on match days. 
Importantly, this study revealed that whilst one approach may not be successful in all stadia settings there is a case for engaging men in health issues in the community setting, during their leisure time and more specifically at an English Premier League football club and on a match day. In this instance, health related awareness and engagement methods that encroached on men's match day experiences (i.e., health stations and leaflets) were not successful as the majority of male football fans appeared to have a match day ritual (i.e., catch a glimpse of the players as they park their cars, meet with friends, navigate their way inside the stadium and get to their seats) during which, they did not like to be disturbed. Having said this, it would appear that practitioners and researchers can be successful in communicating with and engaging men in health information in this, or similar settings, both at the event and after the event (via 'take home' messages). The findings of this research unravelled important implications which provide guidance for good practice. They are presented below;

\section{Implications for practice}

The findings of this research suggest that in order to successfully promote health behaviours and messages to male football fans on an English Premier League match day, practitioners should aim to adopt a range of subtle, non-invasive approaches that may include multimedia messages or the development of tangible, masculine, club branded promotional materials that allude to published health messages. Furthermore, this research highlighted that men became a more captive audience once inside the stadium setting. Therefore in order to engage male football fans in health behaviours and messages on an English Premier League match day (i.e., a high volume context) 
practitioners and researchers should seek to engage with men within the confines of the football stadium rather than outside the stadium where it is typically busy and distracting.

\section{Conclusion and future research}

Through the interpretation of the first hand experiences of the first author within a community setting, this study has identified what aspects of a football in the community health promotion activity worked for men on a match day, and conversely what did not work, and why. Furthermore this study has offered suggestions for effective strategies that will better engage men in health information and behaviours in similar settings. By doing so, this study contributes to an underserved area within health promotion and men's health literature and offers a potential solution to the concerns raised regarding men's under use of health services. ${ }^{49}$ However, there still remains a lack of accessible, research-based evidence examining the effectiveness of different types of innovative approaches to health promotion among men. ${ }^{50}$ Therefore, it can be argued that more contextual evidence is required in order to build a more informed understanding of men's engagement with health services in community settings and subsequently assist in the advancement, and creation of, future men's health promotion initiatives and interventions.

\section{Acknowledgements}

The authors would like to thank the staff of Everton Football Club and Everton in the Community for their support with this research and permission to identify the club explicitly in this publication. 


\section{Notes}

1. White et al., The State of men's health in Europe.

2. White et al., The State of men's health in Europe.

3. Townsend et al., Physical activity statistics 2012.

4. Hunt et al., 'Gender differences in family practitioner consultation for common chronic conditions'.

5. White et al., 'Men's health in Europe'.

6. Addis and Mahalik, 'Men, masculinity, and the contexts of help seeking'.

7. White et al., The State of men's health in Europe.

8. Harrison, 'Warning: The male sex role may be damaging to your health'.

9. Courtenay, 'Constructions of masculinity and their influence on men's wellbeing'.

10. Robertson, Understanding Men and Health.

11. Gough and Robertson, Men, Masculinities and Health.

12. Gough, 'The Psychology of Men's Health'.

13. Gough, 'The Psychology of Men's Health'.

14. White and Witty, 'Men's under use of health services- finding alternative approaches'.

15. White and Witty, 'Men's under use of health services- finding alternative 
approaches'.

16. Department of Health, Healthy people, healthy lives.

17. Wilkins and Baker, 'Getting It Sorted'.

18. White et al., The State of men's health in Europe.

19. Witty and White, 'The Tackling Men's Health Evaluation Study'.

20. Pringle et al., 'The pre-adoption demographic and health profiles of men participating in a programme of men's health delivered in English Premier League football clubs'.

21. Dunn et al., 'Kicking the habit'; Pringle et al., 'The pre-adoption demographic and health profiles of men participating in a programme of men's health delivered in English Premier League football clubs and Robertson et al., 'It's fun, fitness and football really'.

22. White and Witty, 'Men's Health and Sporting Venues'.

23. Robinson et al., 'Working towards men's health'.

24. Robertson and Williamson, 'Men and health promotion in the UK'.

25. Carmichael and Miller, 'The challenges of practitioner-research'.

26. Walsh et al., 'Social marketing for public health'.

27. Wilkins and Baker, 'Getting It Sorted'.

28. Carmichael and Miller, 'The challenges of practitioner-research'.

29. Robson, Real world research; Jarvis, 'The practitioner-researcher in nursing' and Gray, Doing research in the real world.

30. Carmichael and Miller, 'The challenges of practitioner-research'.

31. Tedlock, 'Ethnography and Ethnographic Representation'.

32. Atkinson and Hammersley, 'Ethnography and participant observation' and Clandinin and Connelly, Narrative inquiry.

33. Knowles and Telfer, 'The where, what, why of reflective practice'; Schinke et al., 'Toward cultural praxis and cultural sensitivity' and Knowles et al., Reflective practice in the sport and exercise sciences.

34. Polkinghorne, Narrative knowing and the human science; Tedlock, 'Ethnography and Ethnographic Representation' and Knowles et al., 'Developing the Reflective Sports Coach'.

35. Heider, What do people do? Dani auto-ethnography'.

36. Crotty, The foundations of social research.

37. Mitchell and Charmaz, 'Telling tales and writing stories- postmodern visions and realist images in ethnographic writing'.

38. Sparkes, 'Narrative analysis'.

39. Elo and Kyngäs, 'The qualitative content analysis process'.

40. Ryba et al., 'Towards a conceptual understanding of acute cultural adaptation'.

41. Shenton, 'Strategies for ensuring trustworthiness in qualitative research projects'.

42. Witty and White, 'The Tackling Men's Health Evaluation Study.

43. Richardson and O'Dwyer, 'Football Supporters and Football Team Brands'.

44. Deutsch, 'Gender Differences in Cognition'.

45. White and Witty, 'Men's Health and Sporting Venues'.

46. White and Witty, 'Men's under use of health services- finding alternative approaches'.

47. Robertson et al., 'It's fun, fitness and football really'.

48. Wilkins and Baker, 'Getting It Sorted'.

49. Gough, 'The Psychology of Men's Health'.

50. Robinson et al., 'Working towards men's health'. 


\section{References}

Addis, M. and J. Mahalik. 'Men, masculinity, and the contexts of help seeking'. American Psychologist 58 (2003): 5-14.

Atkinson, P. and M. Hammersley. 'Ethnography and participant observation'. In Strategies of Qualitative Inquiry, ed. N. Denzin and Y. Lincoln, 111-136. London: Sage, 1994.

Carmichael, J. and K. Miller. 'The challenges of practitioner research: Some insights into collaboration between Higher and Further Education in the LfLFE project'. In What a difference a pedagogy makes: researching lifelong learning and teaching. 
Proceedings of 3rd International CRLL Conference 700-702. Glasgow: Centre for Research in Lifelong Learning, 2006.

Clandinin, D. and F. Connelly. Narrative inquiry: experience and story in qualitative research. San Francisco, CA: Jossey-Bass, 2000.

Courtenay, W. 'Constructions of masculinity and their influence on men's wellbeing: A theory of gender and health'. Social Science and Medicine 50 (2000): 1385-1401.

Crotty, M. The foundations of social research: Meaning and perspective in the research process. London: Sage, 1998.

Department of Health. Healthy people, healthy lives: our strategy for public health in England. London: Department of Health, 2010.

Deutsch, R. 'Gender Differences in Cognition'. Presentation, Ad Club of New York, 29/10/2009.

Dunn, K., B. Drust, D. Flower, and Richardson, D. 'Kicking the habit: a biopsychosocial account of engaging men recovering from drug misuse in regular recreational football'. Journal of Men's Health 8 (2011): 233.

Elo, S. and H. Kyngäs. The qualitative content analysis approach. Journal of Advanced Nursing 62 (2008): 107-115. 
Gilbourne, D. and D. Richardson. 'Tales from the field: Personal reflections on the provision of psychological support in professional soccer'. Psychology of Sport and Exercise 7 (2006): 325-337.

Gough, B. 'The Psychology of Men's Health: Maximising Masculine Capital'. Health Psychology 32 (2013): 1-4.

Gough, B. and S. Robertson. Men, Masculinities and Health: Critical Perspectives. Hampshire, England: Palgrave Macmillan, 2010.

Gray, D. Doing research in the real world. London: Sage, 2004.

Harrison, J. 'Warning: The male sex role may be damaging to your health'. Journal of Social Issues 34 (1978): 65-86.

Heider, K. 'What do people do? Dani auto-ethnography'. Journal of Anthropological Research 31 (1975): 3-17.

Hunt, K., G. Ford, L. Harkins, and S. Wyke. 'Are women more ready to consult than men? Gender differences in family practitioner consultation for common chronic conditions'. Journal of Health Services Research and Policy 4 (1999): 96-100.

Jarvis, P. 'The practitioner-researcher in nursing'. Nurse Education Today 20 (1998): 30-35. 
Jones, G. 'Performance excellence: A personal perspective on the link between sport and business'. Journal of Applied Sport Psychology 14 (2002): 268-281.

Knowles, Z., D. Gilbourne, B. Cropley, and L. Dugdill. Reflective practice in the sport and exercise sciences: Contemporary issues. London: Routledge, 2013.

Knowles, Z., D. Gilbourne, and V. Tomlinson, V. 'Reflections of the application of reflective practice for supervision in applied sport psychology'. The Sport Psychologist 21 (2007): 109-122.

Knowles, Z. and T. Telfer. 'The where, what, why of reflective practice'. In Exploring Sport and Fitness, ed. C. Heaney, B. Oakley, and S. Rea. London: Routledge, 2009.

Lee, C. and R. Owens. The psychology of men's health. Buckingham: Open University Press, 2002.

Mitchell, R. and K. Charmaz. 'Telling tales and writing stories- postmodern visions and realist images in ethnographic writing'. In Doing Ethnographic ResearchFieldwork Settings, ed. S. Grills. London: Sage, 1996.

Polkinghorne, D. Narrative knowing and the human sciences. Albany: University of New York Press, 1988. 
Pringle, A., S. Zwolinsky, A. Smith, S. Robertson, J. McKenna and A. White. 'The pre-adoption demographic and health profiles of men participating in a programme of men's health delivered in English Premier League football clubs'. Public Health 125 (2011): 411-416.

Richardson, B. and E. O’Dwyer. 'Football Supporters and Football Team Brands: A Study in Consumer Brand Loyalty'. Irish Marketing Review 16 (2003): 43-51.

Robertson, S. Understanding Men and Health. Masculinities, Identity and Well-being. Berkshire, England: Open University Press, 2007.

Robertson, S. and R. Williams. 'Men: showing willing'. Community Practitioner 82 (2009): 34-35.

Robertson, S. and P. Williamson. 'Men and health promotion in the UK: Ten years further on?' Health Education Journal 64 (2005): 293-301.

Robertson, S., S. Zwolinsky, A. Pringle, J. McKenna, A. Daly-Smith, and A. White. 'It's fun, fitness and football really: a process evaluation of a football based health intervention for men'. Qualitative Research in Sport, Exercise and Health 5 (2013): 419-439.

Robinson, M., S. Robertson, J. McCullagh, and S Hacking. 'Working towards men's health: Findings from the Sefton men's health project'. Health Education Journal 69 (2010): 139-149. 
Robson, C. Real world research: a resource for social scientists and practitioner researchers. Oxford: Blackwell, 1993.

Ryba, T., S. Haapanen, S. Mosek, and K. Ng. 'Towards a conceptual understanding of acute cultural adaptation: a preliminary examination of ACA in female swimming'. Qualitative Research in Sport, Exercise and Health 4 (2012): 80-97.

Schinke, R., K. McGannon, W. Parham, and A. Lane. 'Toward cultural praxis and cultural sensitivity: Strategies for self-reflective sport psychology practice'. Quest 6 (2012): 34-46.

Shenton, A. 'Strategies for ensuring trustworthiness in qualitative research projects'. Education for Information 22 (2004): 63-75.

Sparkes, A. Narrative analysis: Exploring the whats and hows of personal stories. In Qualitative Research in Health Care, ed. I. Holloway. Maidenhead: Open University Press, 2005.

Tedlock, B. 'Ethnography and Ethnographic Representation'. In The handbook of qualitative research, ed. N. Denzin and Y. Lincoln. Thousand Oaks: Sage, 2000.

Townsend, N., P. Bhatnagar, K. Wickramasinghe, P. Scarborough, C. Foster, and Rayner, M. Physical activity statistics 2012. British Heart Foundation: London, 2012. 
Walsh, D., R. Rudd, B. Moeykens, and T. Moloney. 'Social marketing for public health'. Health Affairs 12 (1993): 104-119.

White, A., B. De Sousa, R. De Visser, R. Hogston, S. Madsen, P. Makara, N. Richardson, and W. Zatonski. The State of men's health in Europe. Luxembourg: European Commission, 2011.

White, A., B. De Sousa, R. De Visser, R. Hogston, S. Madsen, P. Makara, M. McKee, G. Raine, N. Richardson, N. Clarke, and W, Zatonski. 'Men's health in Europe'. Journal of Men's Health 8 (2011): 192-201.

White, A., S. Zwolinsky, A. Pringle, J. McKenna, A. Daly-Smith, S. Robertson, and R. Berry. Premier League Health: A national programme of men's health promotion delivered in/by professional football clubs. Final Report 2012. Leeds: Centre for Men's Health and Centre for Active Lifestyles, Leeds Metropolitan University. 2012.

White, A. and K. Witty. 'Men's under use of health services- finding alternative approaches'. Journal of Men's Health 6 (2009): 95-97.

White, A. and K. Witty. 'Men's Health and Sporting Venues'. Journal of Men's Health 6 (2009): 273.

Wilkins, D. and P. Baker. 'Getting It Sorted: a policy programme for men's health'. London: Men's Health Forum, 2004. 
Witty, K. and A. White. 'The Tackling Men's Health Evaluation Study'. Centre for Men's Health: Leeds Metropolitan University, 2010. 